\title{
Abstract A general-purpose, computer-generated, multi-field tachistoscope
}

\author{
LAWRENCE A. SCANLAN, University of Ilinois, Aviation Research Laboratory*
}

Careful control of the physical characteristics of stimuli is basic to the study of the human perceptual system. For several decades the Dodge type tachistoscope has allowed adequate control of two or three stimulus fields. During this time, the limitation on the number of stimulus fields imposed by the half-silvered mirror method of combining fields was not a serious limitation. However, more recently, the nature of the experimental questions being asked has created a requirement for more tachistoscopic fields.

A few researchers have addressed themselves to this problem and have described special-purpose devices built to satisfy their particular research requirements (Eriksen, Schurman, \& Richter, 1969; Mayzner, Tresselt, \& Helfer, 1967; Wojuaroski, Bachman, \& Pollack, 1971). Little or no work has been directed towards creating a general-purpose, multi-field tachistoscope capable of meeting changing research needs without modification. The present paper describes a computer-generated display system intended to meet this objective.

The first step in the design of any display system is a careful enumeration of the necessary and desirable characteristics the display should possess. The second step involves an examination of all potentially applicable display devices and their advantages and disadvantages for the particular problem. Both of these steps are discussed in detail elsewhere (Scanlan, Note 1). Scanlan concludes that two distinct display systems are necessary if all types of stimuli are to be employed. Highly complex photograph-like stimuli cannot be accommodated by digital computer/electronic display systems because of the extremely high data storage and data rate requirements. However, for less complex stimuli, a computer-driven plasma display/memory panel will result in an excellent tachistoscope.

The Digivue plasma panel is a commercially available display device that conceptually can be thought of as a matrix of $512 \times 512$ individually addressable neon discharge cells. The display is constructed in such a manner that once a cell has been turned on it will remain on until it is actively turned off. This characteristic gives the display an inherent memory and removes the requirement for refreshing the display every few milliseconds. The panel is digitally addressed and has a resolution of 60 cells per inch.

The panel is interfaced to a Direct Memory Access (DMA) channel of a Raytheon 704 computer. A simple double register controller synchronizes the display and the computer. The Raytheon 704 minicomputer currently being used has a 16 -bit word length, $24 \mathrm{~K}$ words of memory, a nine-track magnetic tape drive, card reader, priority interrupt and an internal real-time clock; however, the program can be implemented on a much smaller machine.

There are two distinct phases in the implementation of any display. The first is the display definition phase and the second is the actual generation of the display. For a special-purpose display, the definition phase consists of writing down the stimuli that are to be shown. In the case of a general-purpose display, the definition phase causes special problems. The stimuli to be displayed are not known until a specific experimenter uses the tachistoscope. Because of this, a general-purpose tachistoscope requires soft ware for both the definition phase and the generation phase.

The stimulus definition phase of the software should allow for maximum flexibility in the type of stimuli that can be accommodated while keeping the use of the program as simple as possible. This was accomplished by making the stimulus definition software a set of FORTRAN subroutines. FORTRAN was chosen as the source language because of its general availability, relative standardization, and wide usage. The use of subroutines allows the user to have access to the full computational capability of FORTRAN while making the complexity of the definition procedures transparent.

The stimulus definition routines allow for the definition of symbols, elements, and element presentation orders. Symbols are individual stimuli such as letters or shapes that are defined by the user. An element consists of a symbol at a particular position on the display and specifies the time a symbol should be displayed and the time between the current element and the next element. Additionally, there are seven modes of display which allow for considerable flexibility in display definition. The order-of-element routines allow specification of the temporal sequence of element presentation and include the option of repeating sequences of elements a number of times.

The output of the stimulus definition program consists of four records for every trial. The records are written on magnetic tape for use by the display generation program. The magnetic tape serves as the

\footnotetext{
*Present address: Hughes Aircraft Company, Display Systems and Human Factors Department, Building 6. MS D-120. Culver City. California 90230.
} 
communication link between the two programs, thus allowing the generation program to run on a large batch-processing computer and the display program to run on a small mini-computer. This requires that stimuli be generated prior to experimentation but has the advantage of reducing the size and cost of the mini-computer.

The display generation program reads four records per experimental trial from the magnetic tape. Because of the processing that was done during the definition phase, these four records require very little processing at display time. The display program is, therefore, relatively simple and merely controls the output timing.

The tachistoscope program has been used in a number of experimental investigations and has proven to be highly versatile and reliable. By adapting the two-program approach, the stimulus definition program is independent of the particular computer being used, and only the relatively simple display generation program would require modification for use at a new laboratory. Additionally, the cost of the mini-computer is minimized by placing the burden of the computation in the definition program.

\section{REFERENCE NOTE}

1. Scanlan. L. A. Advanced display technology applied to general purpose tachistoscopes. In preparation.

\section{REFERENCES}

Eriksen, C. W.. Schurman. D. L., \& Richter, O. N-channel tachistoscopes. Behavior Research Methods \& Instrumentation, 1969, 1, 119-122.

Mayzner, M. S., Tresselt, M. E., \& Helfer, M. S. A research strategy for studying certain effects of very fast sequential input rates on the visual system. Psychonomic Monograph Supplements, 1967, 2(5. Whole No. 21).

Wojuaroski, L., Bachman, K., \& Pollack, I. High-speed point plotting with computer-controlled displays. Behavior Research Methods \& Instrumentation, 1971, 3, 210-211. 